\title{
Screening of Filamentous Fungi to Identify Biocatalysts for Lupeol Biotransformation
}

Tatiane C. de Carvalho ${ }^{1}$, Aline M. Polizeli ${ }^{1}$, Izabel C. C. Turatti ${ }^{1}$, Marcela E. Severiano ${ }^{2}$, Carlos E. de Carvalho ${ }^{2}$, Sérgio R. Ambrósio ${ }^{2}$, Antônio E. M. Crotti ${ }^{2}$, Uir S. de Figueiredo ${ }^{3}$, Paulo C. Vieira ${ }^{4}$ and Niege A. J. C. Furtado ${ }^{1, *}$

1 Faculdade de Ciências Farmacêuticas de Ribeirão Preto, Universidade de São Paulo, Ribeirão Preto, SP, 14040-903, Brazil; E-Mails: carvalho_tc@ yahoo.com.br (T.C.C.); alinepolizeli@gmail.com (A.M.P.); izcristu@usp.br (I.C.C.T.)

2 Núcleo de Pesquisa em Ciências Exatas e Tecnológicas, Universidade de Franca, Franca, SP, 14404-600, Brazil; E-Mails: marcellaes@hotmail.com (M.E.S.); denossauro7@gmail.com (C.E.C.); sergioambrosio@unifran.br (S.R.A.); millercrotti@unifran.br (A.E.M.C.)

3 Instituto de Ciências Exatas e da Terra, Universidade Federal de Mato Grosso, MT, 78060-900, Brazil; E-Mail: uirs@terra.com.br (U.S.F.)

4 Centro de Ciências Exatas e de Tecnologia, Universidade Federal de São Carlos, SP, 13565-905, Brazil; E-Mail: paulo@dq.ufscar.br (P.C.V.)

* Author to whom correspondence should be addressed; E-Mail: niege@fcfrp.usp.br; Tel.: +55-16-36024305; Fax: +55-16-36024178.

Received: 11 August 2010; in revised form: 30 August 2010 / Accepted: 30 August 2010 / Published: 1 September 2010

\begin{abstract}
The goal of the study was to evaluate the ability of filamentous fungi to biotransform the pentacyclic triterpene lupeol. The microbial transformations were carried out in shake flasks in different media. Experiments were also run with control flasks. Samples of each culture were taken every 24 hours, extracted with ethyl acetate, and analyzed by GC-MS. The biotransformation of lupeol by Aspergillus ochraceus and Mucor rouxii afforded two compounds in each culture, which were detected in the cultures developed for more than seven days only in the Koch's K1 medium. The obtained data demonstrated that $A$. ochraceus is a good biocatalyst to introduce double bonds in the lupeol structure, whereas $M$. rouxii exhibits ability to biocatalyze oxygen insertions in that pentacyclic triterpene. Mass spectrometry was demonstrated to be an efficient analytical method to select promising biocatalysts for the compound investigated in this study. The
\end{abstract}


biotransformation processes were influenced by the culture medium and incubation period. The obtained results open the perspective of using $A$. ochraceus and $M$. rouxii in pentacyclic triterpene biotransformations.

Keywords: biocatalysts; biotransformation; filamentous fungi; lupeol; mass spectrometry

\section{Introduction}

Triterpenes are among the most abundant natural products in the plant kingdom and exhibit huge structural diversity [1]. Among them, pentacyclic triterpenes of the lupane type, such as lupeol, betulin and betulinic acid, have been reported to have interesting bioactivities including antiviral, in particular against to human immunodeficiency virus [2,3], herpes simplex virus [4], and Epstein-Barr virus [5], anti-inflammatory [6] and antitumor against human melanoma and other types of human malignancies [7,8].

Even though more than 100 triterpene skeletons have been reported in Nature [9], hundreds of new derivatives have been synthesized [3,10]. Modifications of the parent structure may produce new potentially interesting derivatives with better pharmacokinetic properties [3], new mechanisms of action [11] and fewer unwanted side effects [12]. Bevirimat, which has entered clinical phase II evaluation in patients, for example, is a derivative of betulinic acid with anti HIV-1 activity [13,14]. NVX-207, another betulinic acid derivative with antitumor activity, is considered a candidate well suited for clinical development [15]. Most of these derivatives are obtained by synthetic approaches [10], although biotransformation processes have also been used in order to target positions more difficult to functionalize by chemical methods.

A number of betulin, betulinic and betulonic acids derivatives have been produced by biotransformation processes [16,17], but no previous studies on the biotransformation of the triterpene lupeol (Figure 1) have been reported. Lupeol is produced by many plants and, hence, is more available than betulin, betulinic and betulonic acids [18].

Figure 1. Chemical structure of lupeol.

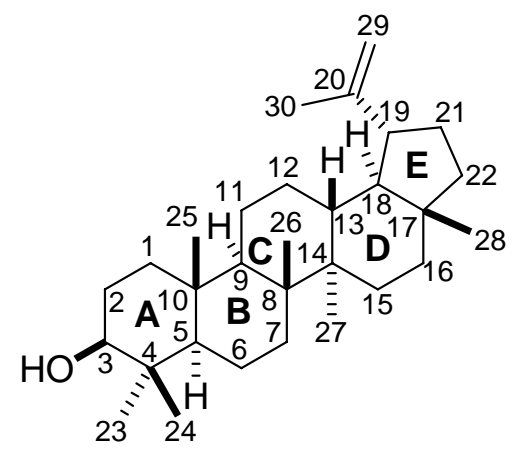

Compared to chemical reagents microbial processes have the advantage of specificity, and of operation at relatively low temperatures without the requirement for potentially polluting heavy-metal 
catalysts [19]. Pure enantiomers have been produced by biotransformation processes, which are considered as a cheap and environmentally friendly alternative to chemical synthesis reactions [20].

Filamentous fungi are versatile and robust organisms having enormous potential for biotransformation of a variety of substrates [21,22]. Thus, the goal of this study was to evaluate the ability of a collection of filamentous fungi to biotransform the pentacyclic triterpene lupeol using different medium constituents, since literature data highlighted the need to evaluate different culture conditions in order to identify efficient biocatalysts.

\section{Results and Discussion}

The following filamentous fungi were found capable of biotransforming lupeol: Aspergillus ochraceus and Mucor rouxii. The abilities of these fungi were demonstrated only when the fungi cultures were developed in the Koch's K1 medium. In addition, the biotransformation products were only detected after a specific incubation time, indicating the influence of the incubation time on the biotransformation reactions.

Medium composition usually plays an important role in biotransformation processes, since different nutrients may affect the functional and structural development of the fungi. In addition, the type and concentration of cosolvents used to dissolve a water insoluble substrate in the culture medium may affect the microorganism growth, as well as the bioconversion yield. Substrate addition should be always performed in such a way that exactly the same amount of substrate, dissolved in the cosolvent, should be added to the cultures, at a concentration previously determined, in order to avoid toxicity problems.

The time course of the biotransformation process is another key issue and is dependent on the growth characteristics of the microorganisms, the culture conditions, the substrate concentration and the type of reaction.

The seed medium was used in order to increase the biomass of the cultures and only after the end of the growth phase, the biomass of each culture was transferred to Czapek and Koch's K1 media, which were used in the biotransformation step. The choice of this strategy is due to the fact that the enzymes produced during the stationary phase are less specific than those produced during the growth phase. The glycosyltransferases produced in the secondary metabolism, for example, are capable of catalysing reactions with a larger number of substrates when compared with those produced in the primary metabolism [23]. The obtained results suggest that the protocol presented here is useful, but should be performed in different biotransformation media.

The biotransformation of lupeol by A. ochraceus and $M$. rouxii afforded two compounds in each culture, which were detected in the cultures developed for more than seven days. These compounds were the only derivatives detected under GC-MS operating conditions. The GC retention times (RT) of the produced derivatives varied according to the fungus, as well as the relative intensities of some ions, including the molecular ion. The GC retention time of lupeol was $35.4 \mathrm{~min}$.

The mass spectra of lupeol and its biotransformation products were initially obtained at $70 \mathrm{eV}$, which is the electron beam energy used for most spectrum libraries. However, at this energy, the mass spectra of all the biotransformation products were identical, in despite of their different retention times. Peaks of the molecular ions of such compounds could be observed only when the beam energy was set 
at $35 \mathrm{eV}$. The mass spectra obtained displayed a series of ions similar to those observed for lupeol, such as the fragment ions with $\mathrm{m} / \mathrm{z} 189$ and $\mathrm{m} / \mathrm{z}$ 207, which is considered characteristic for the fragmentation of triterpenes with a lupane skeleton bearing a hydroxyl group in position 3 [24]. The electron ionization mass spectra of lupeol $(\mathrm{RT}=35.468)$ and of the derivatives 2 and 3 produced by $A$. ochraceus (retention times of 46.5 and $48.8 \mathrm{~min}$ ) and those produced by M. rouxii (4 and 5, retention times of 46.0 and $48.0 \mathrm{~min}$ ) are shown in Figure 2.

Figure 2. EI-MS spectra (35 eV) of lupeol (1) and its derivatives produced by $A$. ochraceus ( 2 and 3, retention times of $46.5 \mathrm{~min}$ and $48.8 \mathrm{~min}$, respectively), and by $M$. rouxxi ( 4 and 5 , retention times of 46.0 and $48.0 \mathrm{~min}$ ).
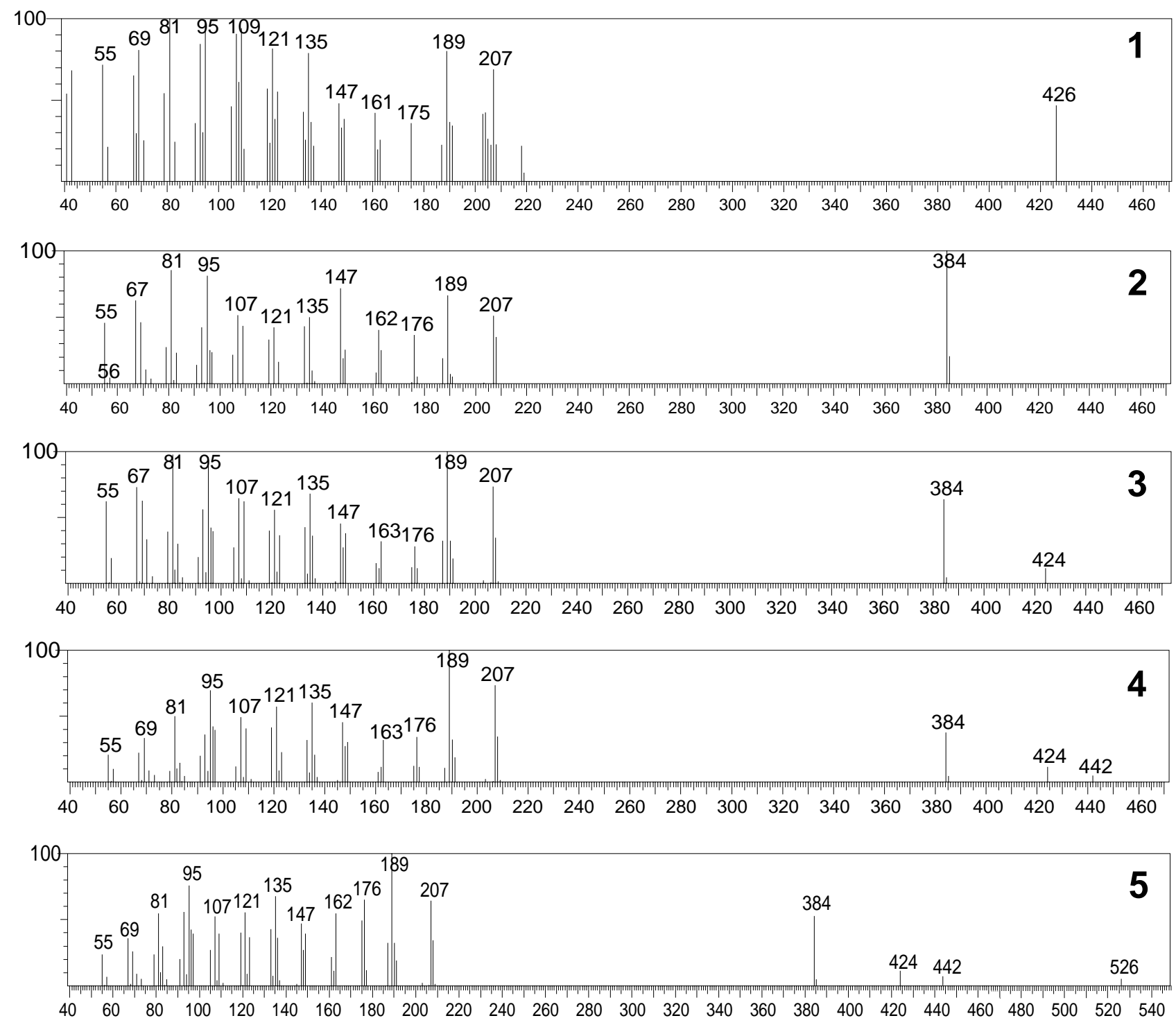

The identification of the biotransformation products mostly have been made on the basis of nuclear magnetic resonance (NMR) data [25,26]. However, due to the complexity of the reaction media obtained from the fungi used in this study and the small amounts of the obtained extracts (range from 5 to $10 \mathrm{mg}$ ), the isolation of the lupeol derivatives and their characterization by NMR was not possible. Hyphenated techniques, such as gas chromatography mass spectrometry (GC-MS) and liquid 
chromatography mass spectrometry (LC-MS) have played a key role in the analysis of low amount of complex samples that require separation previously to the identification [27,28]. GC-MS takes the advantage of the possibility of fast identification based on the comparison with library spectra obtained at $70 \mathrm{eV}$ [29], reason for why this technique was used herein. Furthermore, the fragmentation pathways of lupeol and other pentacyclic triterpenes using electron ionization mass spectrometry (EI-MS) have been extensively reported in the literature [24,30-33]. According to those studies, the fragmentation of lupeol is initiated by $\mathrm{C}-14-\mathrm{C}-27$ cleavage and consequent ${ }^{\circ} \mathrm{CH}_{3}$ elimination, as shown in Figure 3. The fragment ions $\mathrm{m} / \mathrm{z} 411$ and $\mathrm{m} / \mathrm{z} 383$ can eventually not be observed, once they can easily decompose in other fragment ions with lower $\mathrm{m} / \mathrm{z}$. Otherwise, the fragment ions $\mathrm{m} / \mathrm{z} 207$ and $\mathrm{m} / \mathrm{z} 189$ have been proposed to be formed as a result of two competitive pathways, which can be used to diagnose the presence of substituents in A, B, C, D or E rings.

Figure 3. Formation of the fragment ions with $m / z 207$ and $m / z$ 189, proposed with basis on $[24,30]$.

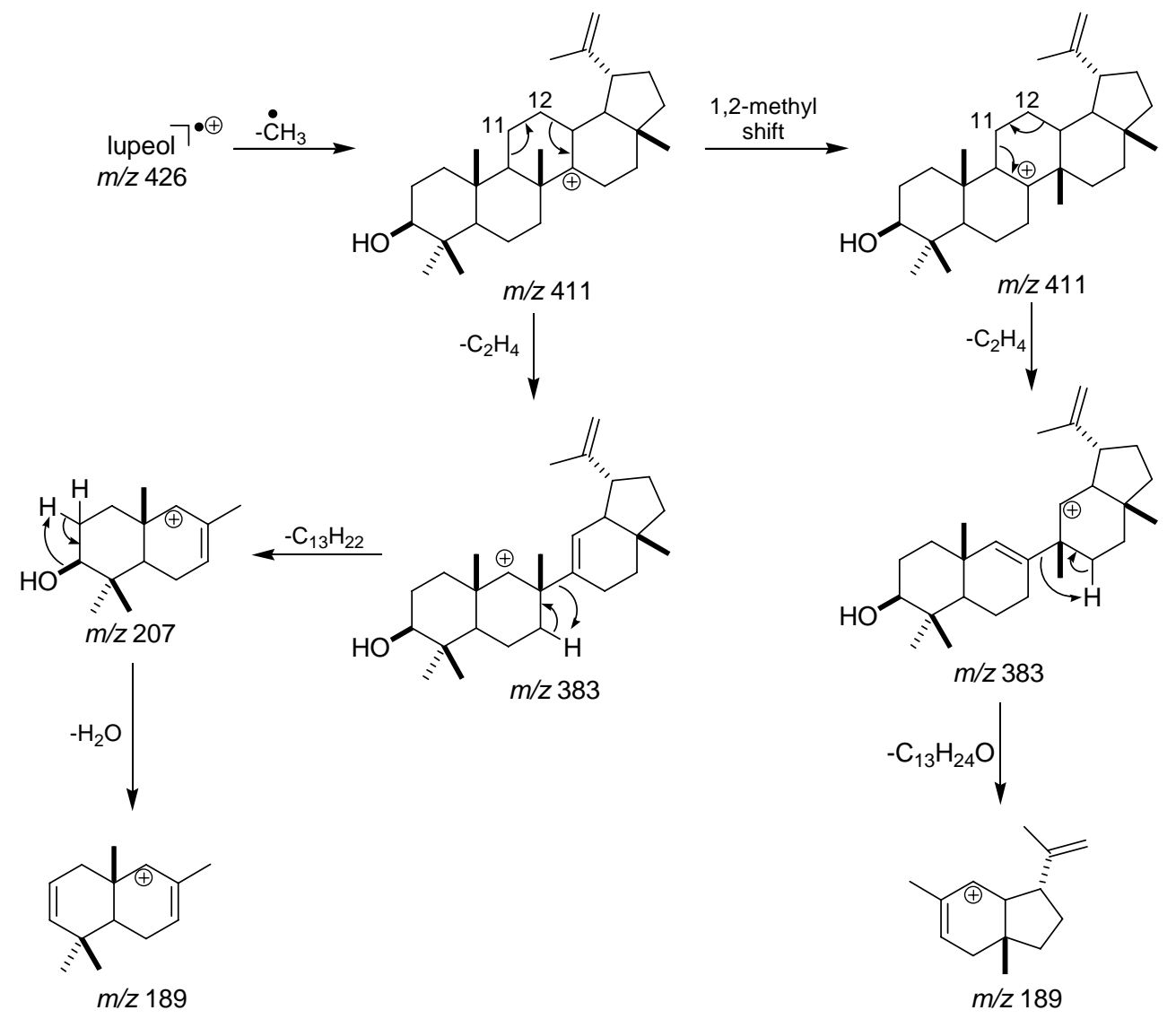

MS spectra of the biotransformation products of lupeol produced by A. ochraceus and M. rouxii were initially obtained at $70 \mathrm{eV}$, and hence compared with the MS spectrum of lupeol, as previously discussed in this paper. At this energy, all the MS spectra were very similar in the $\mathrm{m} / \mathrm{z}$ range from 55 to 207. However, the MS spectra of the biotransformation products differ from the corresponding spectrum of lupeol due to the presence of an ion with $\mathrm{m} / \mathrm{z} 384$ in place of $\mathrm{m} / \mathrm{z} 426$. In principle, this could indicate that these biotransformation products are isomers with molecular weight 384, but exhibiting very different retention times in GC. Otherwise, this could also indicate that the molecular 
ions of such compounds decomposes into fragment ions with lower $\mathrm{m} / \mathrm{z}$ during the flight from the ion source to the analyzer due to the high residual energy content that is transferred to the molecular ion[34]. Thus, in order to confirm the molecular weight of these compounds, MS spectrum of lupeol and its biotransformation products were obtained using lower electron beam energy. The maximum energy that allowed observing the molecular ions of such compounds was found to be $35 \mathrm{eV}$. At this energy, the fragmentation pattern of lupeol was observed to be very similar to that of $70 \mathrm{eV}$, although minor fragment ions, such as $\mathrm{M}^{\bullet+}{ }^{\bullet} \mathrm{CH}_{3}$ and $\mathrm{M}^{\bullet+}{ }^{-} \mathrm{CH}_{3}-\mathrm{C}_{2} \mathrm{H}_{4}$ have not been observed. These spectra revealed that the biotransformation products of lupeol exhibit different molecular ions and structures, as discussed below.

Compounds 2 and 3 were produced by $A$. ochraceus and exhibited retention times of 46.5 and $48.8 \mathrm{~min}$, respectively. Analysis of the MS spectrum of compound 2 (Figure 2) revealed that its molecular ion $(\mathrm{m} / \mathrm{z} 384)$ is 42 mass units lower than lupeol. This mass difference can be due to the elimination of the isopropenyl group at C-19 as propene and subsequent formation of a double bond between C-18 and C-19 (Figure 4). This structural modification can be supported by the intensity of the fragment ion $\mathrm{m} / \mathrm{z} 147$ in the MS spectrum of compound 2, which is higher than in the MS spectrum of compounds 3, 4, 5 and lupeol (see Figure 2). Eliminations of alkyl groups and other size chain have been previously reported to be promoted by this fungus [35]. Otherwise, the molecular ion of compound $3(\mathrm{~m} / \mathrm{z} 424)$ is two mass units lower than that of lupeol ( $\mathrm{m} / \mathrm{z} 426)$, which can be associated with the formation of a double bond. Taking into account that the fragment ions with $\mathrm{m} / \mathrm{z} 207$ and $\mathrm{m} / \mathrm{z}$ 189 did not show mass decrease in comparison with those of lupeol, it is proposed that the double bond is formed between C-11 and C-12 of ring C, as shown in Figure 3. The presence of a double bond in A, $\mathrm{B}, \mathrm{D}$ or E rings would result in the formation of fragment ions with $\mathrm{m} / \mathrm{z} 205$ and $\mathrm{m} / \mathrm{z}$ 187, which are not observed in the spectrum of compound 3. Desaturation by double bond formation has been reported to be promoted by other fungi [36], but this has not been reported for A. ochraceus.

Compounds 4 and 5 were produced by $M$. rouxii and exhibited retention times of 46.0 and $48.0 \mathrm{~min}$, respectively. The MS spectrum of compound $\mathbf{4}$ is very similar to that of lupeol, however, its molecular ion $(\mathrm{m} / \mathrm{z} 442)$ is $16 \mathrm{Da}$ higher than lupeol. This indicates that compound 4 contains an oxygen atom more than lupeol. The presence of the fragment ions $\mathrm{m} / \mathrm{z} 207$ and $\mathrm{m} / \mathrm{z} 189$ lead us to suggest that this atom is likely bound at C-11 or C-12 of the ring C moiety, as shown in Figure 3. Finally, the molecular ion of compound 5 ( $\mathrm{m} / \mathrm{z} 526)$ is 100 mass units higher than the corresponding ion of lupeol ( $\mathrm{m} / \mathrm{z} 426)$. This mass difference is proposed to be due to two addition oxygen atoms and to a prenyl group. Hydroxylation by Mucor rouxii has been previously reported [37] and genes involved in isoprenoid biosynthesis were isolated from Mucor circinelloides [38]. The fragmentation pattern of compound 5 is similar to that of lupeol, despite differences between their structures. This similarity, together with the ions $\mathrm{m} / \mathrm{z} 207$ and $\mathrm{m} / \mathrm{z}$ 189, can indicate that both the oxygen and the isopentenyl groups are also in the $\mathrm{C}$ ring, as shown in Figure 4. 
Figure 4. Proposed structures for the biotransformation products of lupeol, produced by $A$. ochraceus (2 and 3) and M. rouxii (4 and 5).<smiles>CC12CCC=C1C1CCC3C4(C)CCC(O)C(C)(C)[C@H]4CC[C@]3(C)C1CC2</smiles>

M.W. 384

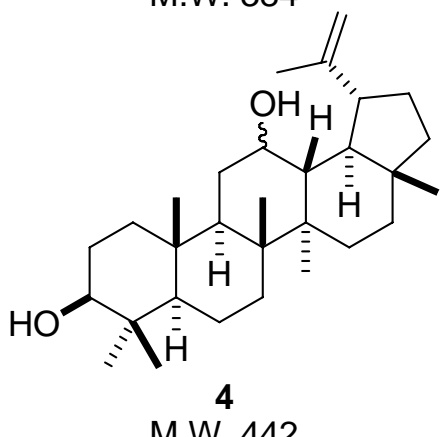

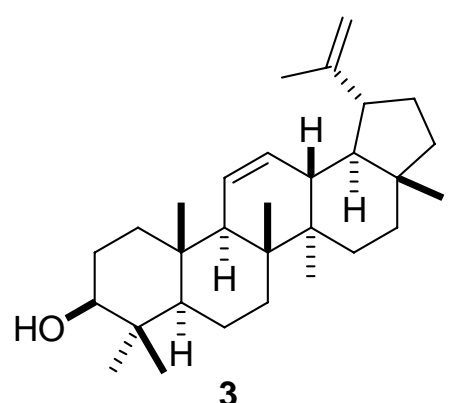

M.W. 424

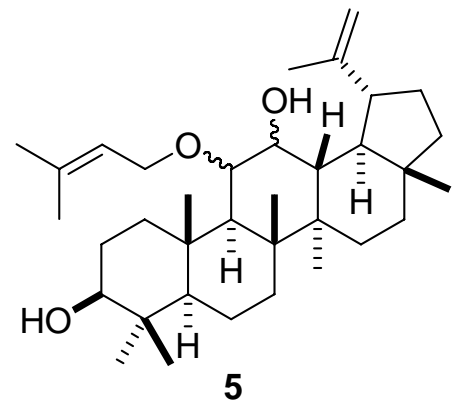

M.W. 526

The time courses of these biotransformations were followed by GC-MS and the relative ratio between the substrate and its transformed products was determined on the basis of the peak area of GC. Biotransformation experiments were carried out for $240 \mathrm{~h}$ and each flask was taken every $24 \mathrm{~h}$, extracted with ethyl acetate, and analyzed by GC-MS. The results are reported in Figures 5 and 6. Lupeol was $38.0 \%$ and $46.0 \%$ consumed by A. ochraceus and M. rouxii, respectively, in 10 days. The relative ratios of compounds 2 and 3 with respect to lupeol were 17.3\% and 11.1\%, respectively, after 7 days incubation, increasing to $19.0 \%$ of compound 2 and remaining unchanged until the 10th day.

Figure 5. Time course in the biotransformation of lupeol by A. ochraceus: (O) lupeol; $(\square)$ compound 2; $(\triangle)$ compound 3.

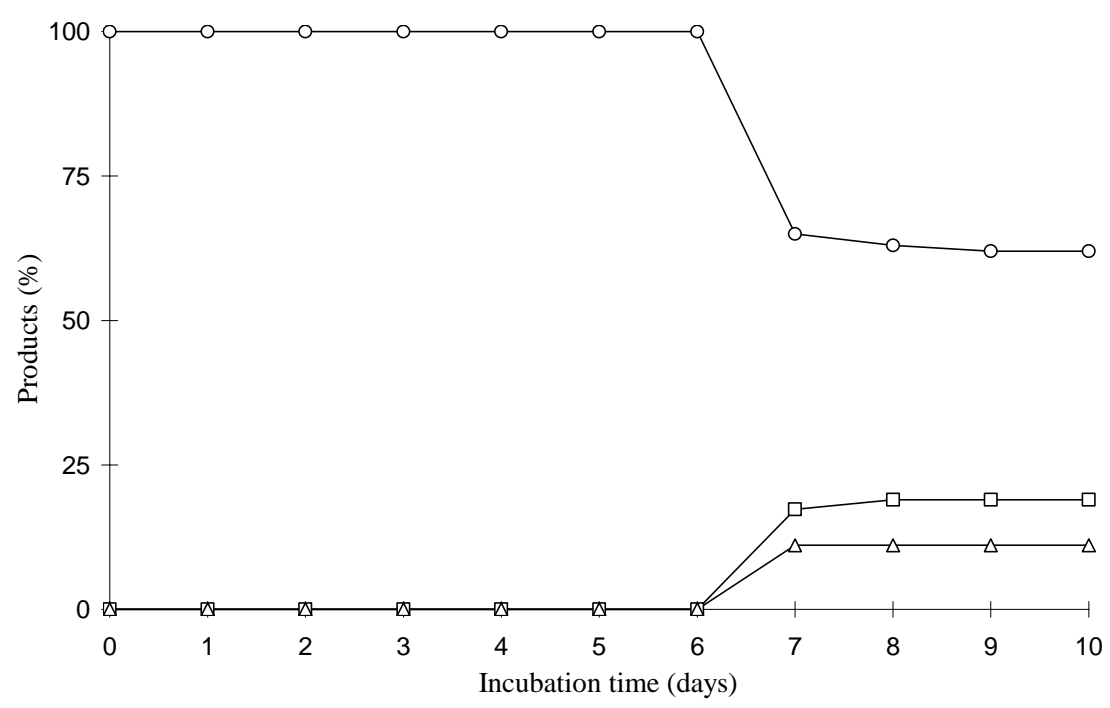


Figure 6. Time course in the biotransformation of lupeol by M. rouxii: (O) lupeol; ( $\square$ ) compound $4 ;(\triangle)$ compound 5.

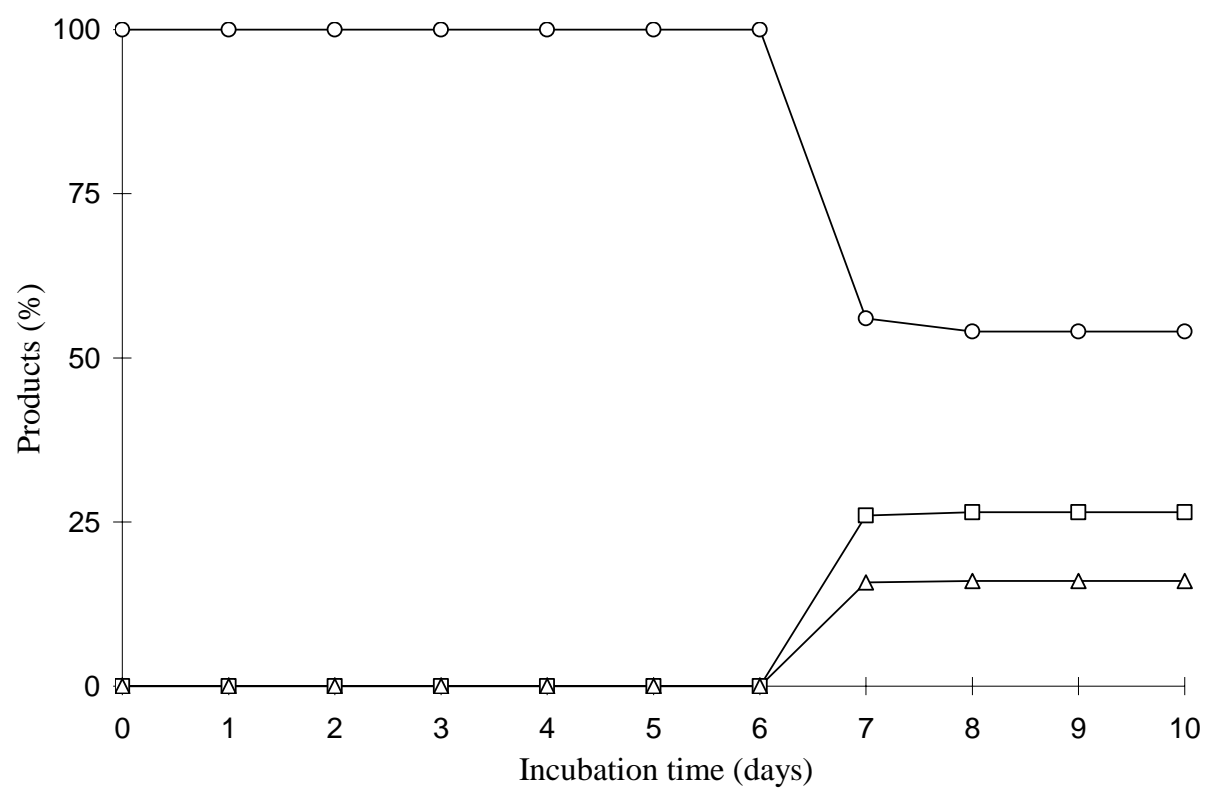

The major product in the biotransformation of lupeol by $M$. rouxii was compound $\mathbf{4}$ and its relative ratio with respect to lupeol was $26.5 \%$ after 10 days incubation. The relative ratio of compound 5 with respect to lupeol was $16.0 \%$ on the 7 th day remaining unchanged until the 10 th day.

Among the filamentous fungi screened for their ability to catalyze the biotransformation of lupeol, A. ochraceus and M. rouxii were found to be the best catalysts. Although the structural elucidation of the biotransformation products must be further confirmed by NMR studies, our data demonstrated that A. ochraceus is a good biocatalyst to introduce double bonds in the lupeol structure, whereas $M$. rouxii exhibits the ability to biocatalyze oxygen insertions into that pentacyclic triterpene. The obtained results open perspectives of using $A$. ochraceus and $M$. rouxii in biotransformations of other pentacyclic triterpenes.

\section{Experimental}

\subsection{Substrate}

Lupeol was isolated from the root bark of Acosmium dasycarpum [39]. The physical and spectral data were in agreement with the reported data for this compound [40].

\subsection{Microorganisms and Maintenance}

The following strains were evaluated regarding their ability to biotransform the pentacyclic triterpene: Aspergillus ochraceus, Chaetomium thermophilum, Humicola grisea var. thermoidea, Mucor rouxii, Phanerochaete chrysosporium, Scytalidium termophylum and Glomerella cingulata. All the strains belong to a collection of fungi cultures of the Biology Department of the School of Philosophy and Sciences of Ribeirão Preto of the University of São Paulo, except the strain of 
Glomerella cingulata, which belongs to the collection of endophyte fungi of the School of Pharmacy of Ribeirão Preto of the University of São Paulo. The microorganisms are stored as a conidial suspension on silica gel (6-12 mesh, grade 40, desiccant activated) at $4{ }^{\circ} \mathrm{C}$ and on slants of solid oatmeal baby food consisting of $0.4 \%(\mathrm{w} / \mathrm{v})$ oatmeal and $1.8 \%(\mathrm{w} / \mathrm{v})$ agar.

\subsection{Biotransformation Procedure}

A two-step culture was performed for biotransformation reactions. An initial inoculum of a suspension of $4 \times 10^{6}$ conidia/mL was added into $125 \mathrm{~mL}$ Erlemeyer flasks containing $15 \mathrm{~mL}$ of seed medium [41]. The flasks were incubated for $48 \mathrm{~h}$ at $30{ }^{\circ} \mathrm{C}$ on a rotary shaker operating at $120 \mathrm{rpm}$ (preculture), except the flasks containing the cultures of Chaetomium thermophilum, Humicola grisea var. thermoidea and Scytalidium termophylum, which were incubated for $72 \mathrm{~h}$ at $40{ }^{\circ} \mathrm{C}$. The resulting mycelia were harvested, rinsed and transferred into $250 \mathrm{~mL}$ Erlenmeyer flasks containing $30 \mathrm{~mL}$ of Czapek (sucrose 3.0\%, $\mathrm{NaNO}_{3}$ 0.2\%, $\mathrm{K}_{2} \mathrm{HPO}_{4}$ 0.05\%, $\mathrm{MgSO}_{4} .7 \mathrm{H}_{2} \mathrm{O} 0.05 \%, \mathrm{KCl} 0.05 \%$ and $\mathrm{FeSO}_{4}$. $7 \mathrm{H}_{2} \mathrm{O} 0.001 \%$ ) or Koch's K1 (glucose $0.18 \%$, bacteriological peptone $0.06 \%$ and yeast extract $0.04 \%$ ) media. Lupeol was added to each flask as a solution in dimethylsulfoxide ( $3 \mathrm{mg}$ dissolved in $600 \mu \mathrm{L}$ ). Control flasks consisted of culture medium with fungi without lupeol, culture medium with dimethylsulfoxide without lupeol and fungi, culture medium with fungi and dimethylsulfoxide without lupeol, culture medium with lupeol without fungi, and only culture medium without anything. Biotransformation experiments were carried out at 30 or $40{ }^{\circ} \mathrm{C}$, depending on the fungus, for $240 \mathrm{~h}$ with shaking at $120 \mathrm{rpm}$. Each flask was taken every $24 \mathrm{~h}$, extracted with ethyl acetate, and analyzed by GC-MS. The ratio between the substrate and its transformed products was determined on the basis of the peak area of GC.

\subsection{GC-MS Analyses}

GC-MS analyses were performed on a Shimadzu GCMS QP2010 Plus instrument equipped with a quadrupole mass analyzer. The following conditions were used: the carrier gas was He at a constant flow of $1.46 \mathrm{~mL} / \mathrm{min}$, the column was DB-5MS (30 $\mathrm{m} \times 0.25 \mathrm{~mm}$ i.d.; film thickness $0.25 \mu \mathrm{m}$, $5 \%$ crosslinked phenyl-methylpolysiloxane). The injector temperature was set at $240{ }^{\circ} \mathrm{C}$, with a split ratio of 1:60. The column temperature was programmed from 50 to $280{ }^{\circ} \mathrm{C}$ at $10{ }^{\circ} \mathrm{C} / \mathrm{min}$; time run, $60 \mathrm{~min}$. The column outlet was inserted directly into the electron ionization source block, operating at $35 \mathrm{eV}$. The scanned mass range was 50-600 amu. The MS spectra obtained were compared with those of Wiley 7.0 spectra library.

\section{Conclusions}

Mass spectrometry was demonstrated to be an efficient analytical method to select promising biocatalysts for the compound investigated in this study. The best biocatalysts were found to be $A$. ochraceus and $M$. rouxii. The biotransformation processes were influenced by the culture medium and incubation period. 


\section{Acknowledgements}

The authors thank to FAPESP (proc. 05/59329-5 and 07/54241-8) and CAPES for the financial support and to Norberto Peporine Lopes (FCFRP-USP) for important suggestions in the GC-MS experiments.

\section{References}

1. Shibuya, M.; Xiang, T.; Katsube, Y.; Otsuka, M.; Zhang, H.; Ebizuka, Y. Origin of structural diversity in natural triterpenes: direct synthesis of seco-triterpene skeletons by oxidosqualene cyclase. J. Am. Chem. Soc. 2007, 129, 1450-1455.

2. Barroso-González, J.; Jaber-Vazdekis, N.E.; García-Expósito, L.; Machado, J.D.; Zárate, R.; Ravelo, A.G.; Estévez-Braun, A.; Valenzuela-Fernández, A. The Lupane-type triterpene 30-oxo-calenduladiol is a CCR5 antagonist with anti-HIV-1 and anti-chemotactic activities. J. Biol. Chem. 2009, 284, 16609-16620.

3. Qian, K.; Yu, D.; Chen, C.; Huang, L.; Morris-Natschke, S.L.; Nitz, T.J.; Salzwedel, K.; Reddick, M.; Allaway, G.P.; Lee, K.; Anti-AIDS agents 78. Design, synthesis, metabolic stability assessment, and antiviral evaluation of novel betulinic acid derivatives as potent anti-human immunodeficiency virus (HIV) agents. J. Med. Chem. 2009, 52, 3248-3258.

4. Badria, F. A.; Abu-Karam, M.; Mikhaeil, B.R.; Maatooq, G.T.; Amer, M.M. Anti-herpes activity of isolated compounds from frankincense. Biosci. Biotechnol. Res. Asia 2003, 1, 1-10.

5. $\quad$ Nakagawa-Goto, K.; Yamada, K.; Taniguchi, M.; Tokuda, H.; Lee, K.; Cancer preventive agents 9. Betulinic acid derivatives as potent cancer chemopreventive agents. Bioorg. Med. Chem. Lett. 2009, 19, 3378-3381.

6. Nguemfo, E.L.; Dimo1, T.; Dongmo, A.B.; Azebaze, A.G.B.; Alaoui, K.; Asongalem, A.E.; Cherrah, Y.; Kamtchouingl, P. Anti-oxidative and anti-inflammatory activities of some isolated constituents from the stem bark of Allanblackia monticola Staner L.C (Guttiferae). Inflammopharmacology 2009, 17, 37-41.

7. Fulda, S.; Kroemer, G. Targeting mitochondrial apoptosis by betulinic acid in human cancers. Drug Discov. Today 2009, 14, 885-890.

8. Saleem, M.; Murtaza, I.; Tarapore, R.S.; Suh, Y.; Adhami, V.M.; Johnson, J.J.; Siddiqui, I.A.; Khan, N.; Asim, M.; Hafeez, B.B.; Shekhani, M.T.; Li, B.; Mukhtar, H. Lupeol inhibits proliferation of human prostate cancer cells by targeting beta-catenin signaling. Carcinogenesis 2009, 30, 808-817.

9. $\mathrm{Xu}, \mathrm{R} . ;$ Fazio, G.C.; Matsuda, S.P.T. On the origins of triterpenoid skeletal diversity. Phytochemistry 2004, 65, 261-291.

10. Reddy, K.P.; Singh, A.B.; Puri, A.; Srivastava, A.K.; Narender, T. Synthesis of novel triterpenoid (lupeol) derivatives and their in vivo antihyperglycemic and antidyslipidemic activity. Bioorg. Med. Chem. Lett. 2009, 19, 4463-4466.

11. Huang, L.; Yub, D.; Hoa, P.; Leeb, K.; Chen, C. Synthesis and anti-HIV activity of bi-functional triterpene derivatives. Lett. Drug Des. Discov. 2007, 4, 471-478.

12. Petronelli, A.; Pannitteri, G.; Testa, U. Triterpenoids as new promising anticancer drugs. Anticancer Drugs 2009, 20, 880-892. 
13. Martin, D.E.; Blum, R.; Wilton, J.; Doto, J.; Galbraith, H.; Burgess, G.L.; Smith, P.C.; Ballow, C. Safety and pharmacokinetics of Bevirimat (PA-457), a novel inhibitor of human immunodeficiency virus maturation, in healthy volunteers. Antimicrob. Agents Chemother. 2007, 51, 3063-3066.

14. Smith, P.F.; Ogundele, A.; Forrest, A.; Wilton, J.; Salzwedel, K.; Doto, J.; Allaway, G.P.; Martin, D.E. Phase I and II study of the safety, virologic effect, and pharmacokinetics/pharmacodynamics of single-dose 3-O-(3',3'-Dimethylsuccinyl) betulinic acid (Bevirimat) against human immunodeficiency virus infection. Antimicrob. Agents Chemother. 2007, 51, 3574-3581.

15. Willmann, M.; Wacheck, V.; Buckley, J.; Nagy, K.; Thalhammer, J.; Paschke, R.; Triche, T.; Jansen, B.; Selzer E. Characterization of NVX-207, a novel betulinic acid-derived anti-cancer compound. Eur. J. Clin. Invest. 2009, 39, 384-394.

16. Akihisa, T.; Takamine, Y.; Yoshizumi, K.; Tokuda, H.; Kimura, Y.; Ukiya, M.; Nakahara, T.; Yokochi, T.; Ichiishi, E.; Nishino, H. Microbial transformations of two lupane-type triterpenes and anti-tumor-promoting effects of the transformation products. J. Nat. Prod. 2002, 65, 278-282.

17. Bastos, D.Z.L.; Pimentel, I.C.; Jesus, D.A.; Oliveira, B.H. Biotransformation of betulinic and betulonic acids by fungi. Phytochemistry 2007, 68, 834-839.

18. Tolstikova, T.G.; Sorokina, I.V.; Tolstikov, G.A.; Tolstikov, A.G.; Flekhter, O.B. Biological activity and pharmacological prospects of Lupane terpenoids: I. Natural Lupane derivatives. Russ. J. Bioorganic Chem. 2006, 32, 37-49.

19. Hudlicky, T.; Reed, J.W. Applications of biotransformations and biocatalysis to complexity generation in organic synthesis. Chem. Soc. Rev. 2009, 38, 3117-3132.

20. Thomason, M.J.; Rhys-Williams, W.; Lloyd A.W.; Hanlon, G.W. The stereo inversion of 2-arylpropionic acid non-steroidal anti-inflammatory drugs and structurally related compounds by Verticillium lecanii. J. Appl. Microbiol. 1998, 85, 155-163.

21. Faramarzi, M.A.; Badiee, M.; Yazdi, M.T.; Amini, M.; Torshabi, M. Formation of hydroxysteroid derivatives from androst-4-en-3,17-dione by the filamentous fungus Mucor racemosus. J. Mol. Catal., B Enzym. 2008, 50, 7-12.

22. Pekala, E.; Kochan, M.; Carnell, A.J. Microbial transformation of hydroxy metabolites of 1-oxohexyl derivatives of theobromine by Cunninghamella echinulata NRRL 1384. Lett. Appl. Microbiol. 2009, 48, 19-24.

23. Thiericke, R.; Rohr, J. Biological variation of microbial metabolites by precursor-directed biosynthesis. Nat. Prod. Rep. 1993, 10, 265-289.

24. Branco, A.; Pinto, A.C.; Braz-Filho, R. Chemical constituents of Vellozia graminifolia (Velloziaceae). Ann. Braz. Acad. Sci. 2004, 76, 505-518.

25. Sutherland, J.B.; Freeman, J.P.; Heinze, T.M.; Moody, J.D.; Parshikov, I.A.; Williams, A.J.; Zhang, D. Oxidation of phenothiazine and phenoxazine by Cunninghamella elegans. Xenobiotica 2001, 31, 799-809.

26. Duhart, B.T.; Zhang, D.; Deck, J.; Freeman, J.P.; Cerniglia, C.E. Biotransformation of protriptyline by filamentous fungi and yeasts. Xenobiotica 1999, 29, 733-746.

27. Pohl, C.H.; Botha, A.; Kock, J.L.F.; Coetzee, D.J.; Botes, P.J.; Schewe, T.; Nigam, S. Oxylipin formation in fungi: biotransformation of arachidonic acid to 3-hydroxy-5,8-tetradecadienoic acid by Mucor genevensis. Biochem. Biophys. Res. Commun. 1998, 253, 703-706. 
28. Demyttenaere, J.; De Kimpe, N. Biotransformation of terpenes by fungi. Study of the pathways involved. J. Mol. Catal., B Enzym. 2001, 11, 265-270.

29. Tomer, K.B. Separations combined with mass spectrometry. Chem. Rev. 2001, 101, 297-328.

30. Budzikiewicz, H.; Wilson, J.M.; Djerassi, C. Mass spectrometry in structural and stereochemical problems. XXXII. Pentacyclic triterpenes. J. Am. Chem. Soc. 1963, 85, 3688-3699.

31. Ogunkoya, L. Application of mass spectrometry in structural problems in triterpenes. Phytochemistry 1981, 20, 121-126.

32. Heizen, H.; De Vries, J.X.; Moyna, P.; Remberg, G.; Martinez, R.; Tietze, L.F. Mass spectrometry of labelled triterpenoids: thermospray and electron impact ionization analysis. Phytochem. Anal. 1996, 7, 237-244.

33. Assimopoulou, A.N.; Papageorgiou, V.P. GC-MS analysis of penta- and tetra-cyclic triterpenes from resins of Pistacia species. Biomed. Chromatogr. 2005, 19, 586-605.

34. Aguiar, G.P.; Wakabayashi, K.A.L.; Luz, G.F.; Oliveira, V.B.; Mathias, L.; Vieira, I.J.C.; Braz-Filho, R.B.; Crotti, A.E.M. Fragmentation of plumeran índole alkaloids from Aspidosperma spruceanum by electrospray ionization tandem mass spectrometry. Rapid Commun. Mass Spectrom. 2010, 24, 295-308.

35. Saratale, G.D.; Humnabadkar, R.P.; Govindwar, S.P. Study of mixed function oxidase system in Aspergillus ochraceus (NCIM 1146). Indian J. Microbiol. 2007, 47, 304-309.

36. Faramarzi, M.A.; Zolfaghary, N.; Yazdi, M.T.; Adrangi, S.; Rastegar, H.; Amini, M.; Badiee, M. Microbial conversion of androst-1,4-dien-3,17-dione by Mucor racemosus to hydroxysteroid-1,4dien-3-one derivatives. J. Chem. Technol. Biotechnol. 2009, 84, 1021-1025.

37. Lacroix, I.; Biton, J.; Azerad, R. Microbial models of drug metabolism: microbial transformations of Trimegestone ${ }^{\circledR}$ (RU27987), a 3-Keto- $\Delta^{4,9(10)}-19$-norsteroid drug. Bioorg. Med. Chem. 1999, 7, 2329-2341.

38. Velayos, A.; Fuentes-Vicente, M.; Aguilar-Elena, R.; Eslava, A.P.; Iturriaga, E.A. A novel fungal prenyl diphosphate synthase in the dimorphic zygomycete Mucor circinelloides. Curr. Genet. 2004, 45, 371-377.

39. Rocha, R.F.; Lapa, A.J.; Vale, J.R.; Braz-Filho, R.; Silva, S.B. Pharmacological activity of crude and purified extracts from Acosmium dasycarpum (Vog) Yakvol. Cienc. Cult. 1980, 33, 158-162.

40. Burns, D.; Reynolds, W.F.; Buchanan, G.; Reese, P.B.; Enriquez, R.G. Assignment of ${ }^{1} \mathrm{H}$ and ${ }^{13} \mathrm{C}$ spectra and investigation of hindered side-chain rotation in lupeol derivatives. Magn. Reson. Chem. 2000, 38, 488-493.

41. Jackson, M.; Karwoswski, J.P.; Humphrey, P.E.; Kohl, W.L.; Barlow, G.J.; Tanaka, S.K. Calbistrins, novel antifungal agents produced by Penicillium restrictum. J. Antibiot. 1993, 46, 34-38.

Sample Availability: Samples of the compound studied in the present manuscript are available from the authors.

(C) 2010 by the authors; licensee MDPI, Basel, Switzerland. This article is an open access article distributed under the terms and conditions of the Creative Commons Attribution license (http://creativecommons.org/licenses/by/3.0/). 